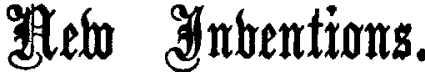

\section{THE SPRING-GRIP CURETTE FOR THE REMOVAL OF ADENOIDS.}

THE blade of the curette is straight and the fenestra rectangular, as shown in the illustration, the cutting portion of the blade being at right angles to the shaft. Up to this point it is practically a Beekmann's curette. To the shaft is fitted, by means of a detachable joint, a long spring, to the terminal end of which is hinged a thin plate which fits accurately into the fenestra of the curette on three sides, but with its anterior limit in contact with the bevelled surface of the blade at about onesixteenth of an inch from the cutting edge. As the curette is pressed on the growth the plate is forced open by the pressure of the growth on the under surface of the plate. The curette travelling backwards and downwards, the growth passes between the blade of the curette and the edge of the plate. On withdrawing the curette the grip on the growth between the plate and the blade is sufficient to extract the growth by its inferior margin. Its advantages over the cage are as follows: (1) it admits of the presence of the guiding forefinger in the post-nasal space as it takes no more room than the open curette and there is therefore no necessity to have a view of the pharynx, so that there is a slight saving of time which is of advantage when operating under gas; (2) the curette cuts cleaner, as the edge does not get blocked by the retention of the growth in its vicinity ; (3) it does not leave the growth hanging in the pharynx, as is sometimes the case with the cage; (4) it removes the growth in a single piece if the stroke is carried through at an even depth and the growth is continuous in structure, never dropping it out if the curette is removed with care from the pharynx; and (5) the time taken in removing the growth from the curette is less than that taken in changing the instrument for another one. I am indebted to Messrs. Mayer and Meltzer of Great Portland-street, London, W., for the care they have taken in carrying out the design.

Mackay MacDonald M.B., B.C. Cantab., Harley-street, w. Senior Clinical Assistant, Throat Department, King's College Hospital.

\section{IMPROVEMENTS IN HANSOMS.}

IN The Lancet of April 18th, p. 1119, we discussed under the heading "The Objections to the Hansom," the various faults to be found in "the gondola of London" and at the same time we expressed our astonishment that no light, comfortable, four-wheeled open vehicles were to be found in London. We now learn that a consignment of small victorias is coming over from Paris, a fact we are very pleased to learn, and we can only say that we wish them fine weather. But with regard to the bansom there has been brought to our notice a new form of hansom which certainly is free from most of the faults to which we took objection as existing in the present style. The cab in question is called the Alington cab and instead of the ordinary doors and guillotine window possesses semicircular doors, with windows in them which move up and down in the ordinary way. These doors are opened or closed simultaneously by the driver and getting into or out of the cab is thereby rendered easy. The cab is fitted with a band-brake acting on the habs of both axles, a piece of apparatus which we think is most desirable. Curiously enough, however, the patentees inform us that the members of the London cab trade, with that hidebound conservatism which is losing our country so much trade, refuse to use the brake on the ground that they never heard of a brake for a two-wheeled vehicle. It is quite true that in the south of England, at any rate, the simple tyre brake acting on both wheels which is so common in foreign countries is never used, the only brake being the iron-shod drag-pole which sticks out behind and on to which the body of the cart is tilted. To our minds the Alington cab is a great improvement upon the ordinary hansom. Of course, if the doors are shut and the windows are open it is draughty, but even with the windows up the ventilation is good and the sensation is that of driving in a small brougham. From a personal trial of the cab we can congratulate the inventor on the comfort and comparative safety of his vehicle The cabs can be seen at, or hired from, Mr. J. E. Gentle, Old Manor Yard, adjoining Earl's Coart Station, but as yet there are only a few plying for hire.

We have also received from Mr. W. F. Stevenson of Boscombe a sketch and description of two improvements applied by him to the ordinary hansom. One is the substitution of a revolving glass hood in place of the guillotine window and the other is the substitution of a wheel on the "gravel iron" in place of the usual loop of iron. Neither of these improvements is new and the latter was brought to our notice in 1900 by Captain Dickson and described in THE LANCET of Sept. 29th, 1900, p. 981. The former modification has been applied to hansoms for some years, but both modifications are among the first to suggest themselves to anybody who studies the matter and we do not for a moment suppose that Mr. Stevenson was aware that his ideas had been anticipated.

\section{TEST-TYPES FOR THE POCKET.}

THIS appliance has been designed for the purpose

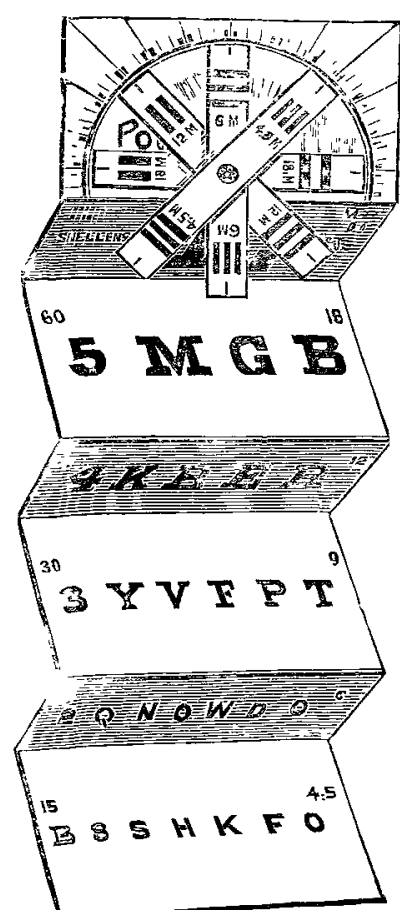
of meeting the difficulty which from time to time arises from not having a convenient and ready form of types for testing the vision in patients' houses. It consists of seven cards, united by strips of linen, measuring $6 \frac{1}{2}$ inches by 4 inches, upon one side of which are printed Snellen's Distance Types and on the other types for reading; in addition the topmost card is perforated in its centre with a revolving pin which secures four strips of stout cardboard. At each extremity is a set of horizontal and vertical lines. These lines vary in thickness from those visible at 18 metres to 12,6 , and 4.50 metres respectively, while behind the lines is printed on the card a graduated arc, indicating the axes which they can be made to assume. This arrangement provides for the testing of cases of astigmatism, and thus the appliance forms a handy, complete, and compact visual test, especially adapted for use in

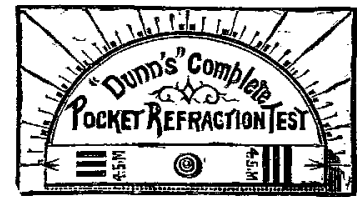
patients' homes. The whole folds into a small space occupying about $6 \frac{1}{2}$ inches by $4 \frac{1}{2}$ inches by th of an inch, and can be readily carried in the pocket. The publisher is Mr. F. Davidson, Optician, 140, Great Portland-street, London, W., who supplies it at a trifling cost.

Percy DUNN, F.R.C.S.Eng.,

Ophthalmic Surgeon to the West London Hospital ; Lecturer Wimpole-street, w. Ophthalmology at the West

Crownhill Convalescent Home.-The annual meeting of the subscribers to the Crownhill Convalescent Home, near Plymouth, was held on May 1st. The report stated that during the past year 259 patients had been admitted. The financial statement showed that the expenditure had amounted to $£ 520$ and that an adverse balance of $£ 29$ remained against the institution. Dr. C. A. Hingston, the founder of the home, was reappointed honorary physician. 


\section{THE LANCET.}

LONDON: SATURDAY, MAY 9, 1903.

\section{"Opticians" and Spectacle Prescribing.}

A CONSIDERABLE amount of feeling has been excited in the minds of many members of the medical profession by the modern claim of spectacle-sellers to possess a degree and kind of scientific knowledge which would render them trustworthy advisers on all matters relating to the employment of the useful instruments in which they deal, and by the modern claim of the commercial bodies with which they are connected, or from which they obtain some kind of licence or diploma, to test the possession of this knowledge by means of examination. It is impossible to traverse the streets without seeing an announcement that So-and-so is an "ophthalmic optician," whatever this grotesque combination of words may be supposed to mean, and that he is not only prepared "to test the sight" of his customers but also to advise them with regard to the appliances by which any defects that he may discover can be rectified. An "optician," according to Dr. JoHnson's definition, is "one skilled in the science of the nature and laws of vision," and "ophthalmic," which does not appear in Jomnsor, is defined by the later authority of WEBSTER to be "that which has relation to the eye," so that the addition of the adjective to the description of a tradesman is at best a pleonasm, and frequently, without doubt, is a misleading one. Those who are thus described, however, have during the last few years not only held themselves out as competent or even exception. ally skilful advisers of the public with respect to their sight, but they have even gone to the length of recommending medicaments as well as spectacles and of selling lotions which have not always proved to be harmless. Quite recently an action was brought by one of these socalled "opticians" against a druggist who had supplied him with ready-prepared "eye lotions" for all cases, one of which lotions was productive of serious injury to the purchaser.

It must be admitted, of course, that spectacles were made and sold by the trade and were freely used by the public, as well as that a Worshipful Company of Spectacle Makers existed, long before the investigation of the eye as an optical instrument had been undertaken by physiologists ; and it is not unworthy of note that the opinions held by the "opticians" of the pre-physiological days with regard to the refraction of the eye and its derangements were wholly and in every respect erroneous. In any book on "optics" written 50 years ago it will be found stated that short-sight is produced by undue convexity of the cornea, with consequent excess of refractive power, and that presbyopia is produced by gradual flattening of the cornea, with consequent gradual diminution of refractive power. Spectacles for short sight were only considered in relation to their immediate effect in affording better distant vision; and, inasmuch as the gradual diminution and ultimate loss of sight in chronic glaucoma were usually attended by a demand on the part of the sufferer for stronger and stronger reading spectacles, it became the custom of the "trade" to attribute the loss of sight to the strength of the glasses and solemnly to utter foolish warnings against the employment of any which were "too strong." Before the days of BREWSTER there was at least no common knowledge of the existence of the function of accommodation or of the possible nature of its derangements and long after his days the old errors were copied from text-book to text-book. In a thousand years physical opticians had done absolutely nothing to attain to any real knowledge of the functions of the eye as a seeing organ or of the various ways in which those functions were liable to be disturbed and but for the labours of physicians they would to-day be very much where they were in China in the days of Confucius or in Egypt in those of the Shepherd Kings.

With the entrance of physicians and physiologists upon the scene all this was changed. The science of physiological optics was created by THOMAS YouxG, the discoverer, among many other things, of astigmatism; and the slowly growing knowledge of the next quarter of a century was fully set forth and systematised in 1864 in the monumental work of DoNDERs, himself the discoverer, again among many other things, both of hypermetropia and of the dependence of myopia upon elongation of the eyeball instead of upon faulty curvature of the cornea-a discovery which at once led to new views of the seriousness of the affection and of the principles upon which its treatment should be conducted. The power of accommodation, first recognised by KEPLER, had been analysed by Young; and to its gradual diminution, instead of to an imaginary "flattening of the cornea," the phenomena of presbyopia at length came to be attributed, with the result that the visual errors thence arising were for the first time corrected on scientific principles. At a still later period the actions or defects of the ocular muscles became the subjects of medical investigation, largely in the United States of America; while the use of prismatic spectacles, first suggested by Giradd-Teulon, was placed upon a scientific foundation by Scheffler of Brunswick. Even more recently, these have to some extent been superseded by surgical operations upon the muscles, either by tenotomy of any which are acting in excess or by advancement of the insertions of their antagonists, measures in respect of which, again, we have to admit a large indebtedness to America. In all this progress, by which the use of spectacles has been raised from a matter of often ignorant routine to the level of a science, every step has been made by medical practitioners, and not a single one by any "optician," either real or so-called; while not the least of its consequences has been to show that the treatment of optical defects of the eyes is in many cases a matter of very grave responsibility, which can only be safely undertaken under the guidance of complete medical and physiological knowledge.

We presume it will be universally admitted that even for the prudent discharge of the proper duties of their tradethat is to say, for the manufacture and sale of spectacles 